\title{
Dasatinib-Induced Colitis in a Patient with Chronic Myelogenous Leukemia
}

\author{
David N. Perdigoto ${ }^{a}$ Sandra Lopes ${ }^{a}$ Francisco Portela ${ }^{a}$ \\ Maria Augusta Cipriano ${ }^{b}$ Luís Toméa $^{a}$ \\ ${ }^{a}$ Gastroenterology Department and ${ }^{b}$ Pathology Department, Coimbra Hospital and University Center, \\ Coimbra, Portugal
}

\section{Keywords}

Dasatinib · Colitis · Hematochezia · Chronic myelogenous leukemia

\section{Colite por Dasatinib em Doente com Leucemia Mieloide Crónica}

\section{Palavras Chave}

Dasatinib · Colite · Hematoquézia · Leucemia mieloide crónica

A 54-year-old man presented to his doctor with bloody diarrhea (4-8 bowel movements/day) that had lasted for 4 weeks. He also complained about occasional bright red hematochezia. Following this consultation, a bacteriological and parasitological stool examination was done and was negative. Afterwards, a colonoscopy showed diffuse papular erythematous areas, more severe in the sigmoid colon, and respective biopsies revealed nonspecific colitis. He was then scheduled for a gastroenterology appointment and at that time he described improvement of his overall condition and spontaneous resolution of the

\section{KARGER}

E-Mail karger@karger.com www.karger.com/pjg
(C) 2017 Sociedade Portuguesa de Gastrenterologia Published by S. Karger AG, Basel

Karcer

Open access

This article is licensed under the Creative Commons AttributionNonCommercial-NoDerivatives 4.0 International License (CC BYNC-ND) (http://www.karger.com/Services/OpenAccessLicense). Usage and distribution for commercial purposes as well as any distribution of modified material requires written permission. diarrhea and hematochezia. The patient had a history of chronic myelogenous leukemia (CML), depression, high blood pressure, and obstructive sleep apnea. He was receiving dasatinib for the CML for two and a half years, following a previous imatinib therapy that failed due to drug resistance. Hematological remission had been achieved with dasatinib 2 months prior to the gastroenterological consultation. A control colonoscopy was performed and showed colonic loss of the normal submucosal vascular pattern with multiple areas characterized by edema, erythematous and papular lesions associated with erosions, small ulcers, and exudation (Fig. 1). This pattern was diffuse throughout the colon but more severe in the descending and sigmoid segments and rectum. The histopathological examination allowed the identification of mild irregular and branched crypts, diffuse lamina propria hemorrhage, and presence of eosinophils, neutrophils, and some eosinophilic crypt abscesses (Fig. 2). Apoptotic bodies and intraepithelial lymphocytes were absent. Cytomegalovirus infection was excluded with sample immunochemistry staining and Clostridium difficile infection was also excluded due to absence of the pathogenic toxin in a stool analysis. These endoscopic and pathological features are consistent with the diagnosis of dasatinib-induced colitis (DIC) $[1,2]$. 

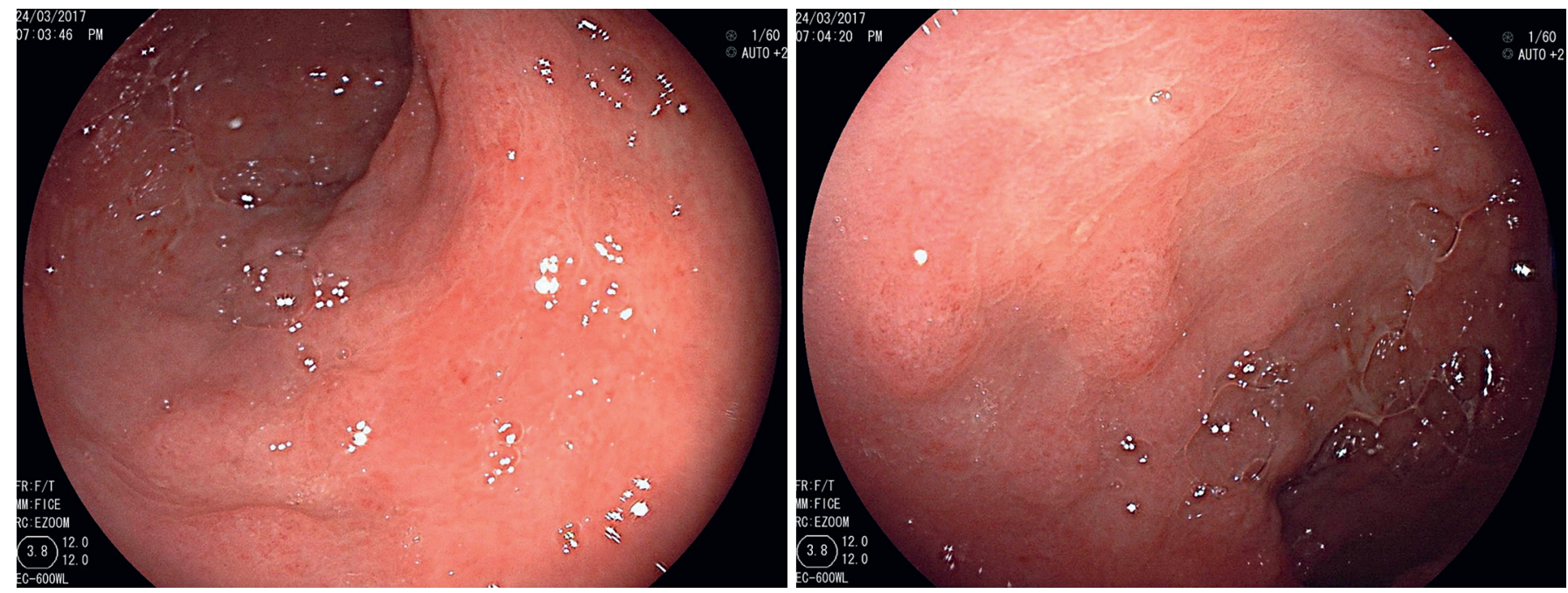

Fig. 1. Colonic mucosa showing papular erythematous lesions, erosions, and exudation.
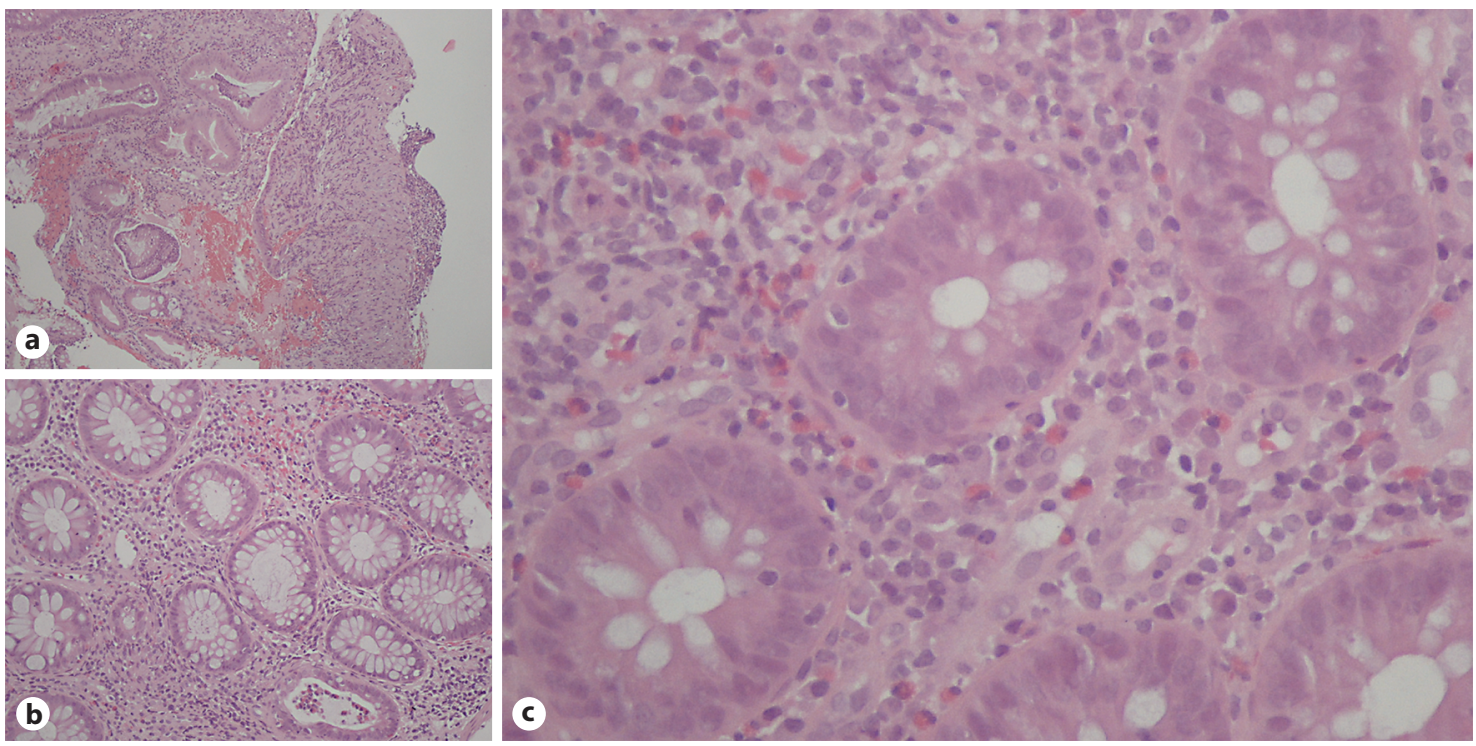

Fig. 2. Pathological findings in the colonic mucosa lesions (hematoxylin and eosin stain): erosion and diffuse lamina propria hemorrhage $(\mathbf{a})(\times 100)$, eosinophilic crypt abscess $(\mathbf{b})(\times 200)$, and inflammatory infiltrate with plasma cells, neutrophils, and eosinophils $(\mathbf{c})(\times 400)$.

Dasatinib is an oral BCR-ABL tyrosine kinase inhibitor that is indicated for CML treatment, particularly after development of imatinib resistance. Dasatinib has several side effects and gastrointestinal hemorrhage has been reported to occur in 2-9\% cases. Although well described in the literature [3-5], DIC is a less common side effect.

The typical presentation is characterized by bloody diarrhea that usually follows weeks to months after the ini- tiation of dasatinib but can also occur several years after treatment. In the majority of cases, the drug therapy needs to be interrupted because of permanent or severe symptoms. Other options are to reduce the drug dose or switch to another tyrosine kinase inhibitor such as nilotinib [2]. In this case, a multidisciplinary meeting was made and the decision was to maintain the treatment because the patient did not develop symptomatic relapse, 
confirmed with two subsequent colonoscopies, executed during gastroenterological follow-up, that showed significant improvement in the mucosal lesions. Additionally, the patient had been shown to be resistant to imatinib and the consequences from withdrawing dasatinib could jeopardize the patient's hematological and global health status.

The endoscopic DIC pattern can be misleading. Therefore, it is important to keep in mind that colitis presenting with bloody diarrhea is an uncommon but possible complication of dasatinib treatment. Infectious conditions must be ruled out, mainly cytomegalovirus infection, which can occur simultaneously.

\section{Statement of Ethics}

As this is a short case report of endoscopic nature (Endoscopic Snapshot), approval from the institutional ethics commission was not necessary. The patient authorized the publication of the data and the patient's anonymity is preserved in the article.

\section{Disclosure Statement}

The authors declare no conflicts of interest.

\section{Author Contributions}

David N. Perdigoto: data acquisition and editing, manuscript drafting. Sandra Lopes: data acquisition and manuscript revision. Maria Augusta Cipriano: pathological editing and manuscript revision. Francisco Portela, Luís Tomé: manuscript revision.
References
1 Ahn H, Kwon J, Sohn S, Kwon J, Kim J, Yoon SS, et al: A case of dasatinib-induced hemorrhagic colitis diagnosed by the lymphocyte transformation test in a chronic myeloid leukemia patient. Indian J Hematol Blood Transfus 2016;32:96-99.

2 Chisti M, Khachani A, Brahmanday G, Klamerus J: Dasatinib-induced haemorrhagic colitis in chronic myeloid leukaemia (CML) in blast crisis. BMJ Case Rep 2013-200610.
3 Nishiwaki S, Maeda M, Yamada M, et al: Clinical efficacy of fecal occult blood test and colonoscopy for dasatinib-induced hemorrhagic colitis in CML patients. Blood 2017;129:126128.

4 Shanshal M, Shakespeare A, Thirumala S, Fenton B, Quick DP: Dasatinib-induced Tcell-mediated colitis: a case report and review of the literature. Acta Haematol 2016;136: 219-228.

5 Yim E, Choi YG, Nam YJ, Lee J, Kim JA: Dasatinib induces severe hemorrhagic colitis in a patient with accelerated phase of chronic myelogenous leukemia. Korean J Intern Med 2016, Epub ahead of print. 